\title{
Corona Virus - The Dental Outlook
}

\author{
${ }^{1}$ Dr. Thorikonda Sai Pravallika*, ${ }^{2}$ Dr. Sheetal Akula, ${ }^{3}$ Dr. Kurnool Balaji, ${ }^{4}$ Dr. Maddela Jyothi, \\ ${ }^{5}$ Dr. Jaidupally Ramvilas Reddy \\ ${ }^{1,4}$ MDS Public Health Dentistry Family Dental Care, Plot No: 316, Pragathi nagar road, Kukatpally, \\ Hyderabad - 500085 \\ ${ }^{2}$ MDS Public Health Dentistry Associate Professor Sri Sai College of Dental Surgery, Vikarabad \\ ${ }^{5}$ MDS Public Health Dentistry Cliniq 32, Shankarpally, Hyderabad \\ ${ }^{3}$ MDS Pedodontics and Preventive Dentistry Family Dental Care, Plot No: 316, Pragathi nagar road, \\ Kukatpally, Hyderabad - 500085
}

\begin{abstract}
Aim: This review provides an overview of the corona virus and to determine the precautionary recommendations to be taken by the Dental Professionals.

Background: Corona virus (COVID-19) in no time has captured the world's attention and is declared as a pandemic by WHO.

Review Results: Dental care settings inevitably carry the risk of infection due to the specificity of the procedures and effective preventive measures can help the spread of the infection.

Conclusion: The outbreak of corona virus had already lead to huge number of deaths and its risk continues to remain high. Infection control measures are necessary to help control the situation.
\end{abstract}

Keywords: Corona virus, Pandemic, Dental considerations

\section{Introduction}

Over the past five decades the emergence of many Transmissible diseases leads to a wide variety of epidemics. Currently Corona outbreak is high alert among medical professionals. Corona virus are a large family of viruses that cause illness ranging from the common cold to more severe diseases such as Middle East Respiratory Syndrome (MERS-COV) and Severe Acute Respiratory Syndrome (SARS-COV) (Mirza et al., 2016).

On $31^{\text {st }}$ of December 2019 it was first reported that an unknown causative pathogen was causing severe and even fatal pneumonia in a seafood market of Wuhan city, Hubei Province, China and later it rapidly spread to other places and countries (WHO, 2020). This virus was finally identified and named by WHO as Corona virus disease (COVID 19) on $11^{\text {th }}$ of February 2020, the seventh family member of corona viruses that infect humans (Peng et al., 2020). The novel Corona virus is a new strain of virus which has not been identified ever before and is now introduced to humans for the very first time. The pandemic spread of the virus, because of its ease and rate of transmission has caused an alarming situation all around the world. Reports have confirmed huge number of cases of corona virus till date (WHO, 2020). However it is considered to be the first pandemic which could be controlled and its outbreak exemplifies ongoing bio threats to global security.

Corona viruses are zoonotic diseases, which are transmitted from animals to humans. They are well established pathogens of humans and animals, with the first virus (HCOV-229E) being isolated from humans in 1965 (Abbas, 2020). Currently, two species of alpha corona viruses HCoV-229E and HCoVNL63 and four species of beta corona viruses HCoV-OC43, HCoV-HKU1, severe acute respiratory syndrome-corona viruses (SARS-COV) and the Middle East respiratory syndrome corona virus (MERSCOV) are known to cause infections in humans (Mirza et al., 2016). Given the high prevalence and wide distribution of corona viruses, the large genetic diversity and frequent recombination of their genomes, and 
increasing human-animal interface activities, novel corona viruses are likely to emerge periodically in humans owing to frequent cross-species infections and occasional spillover events (Fehr et al., 2015).

\section{Characteristics of Virus}

Corona viruses are enveloped non-segmented positive-sense single stranded RNA viruses belonging to the family Coronaviridae and the order Nidovirales (Huang et al., 2020). The distinguishing feature of coronaviruses is the club-shape spike that projects from the surface of the virion. These spikes are a defining feature which gives them the appearance of a solar corona, prompting the name, corona viruses as seen in (figure 1). One interesting aspect of these viruses is their differences in tolerance to genetic variability (Fehr et al., 2015).

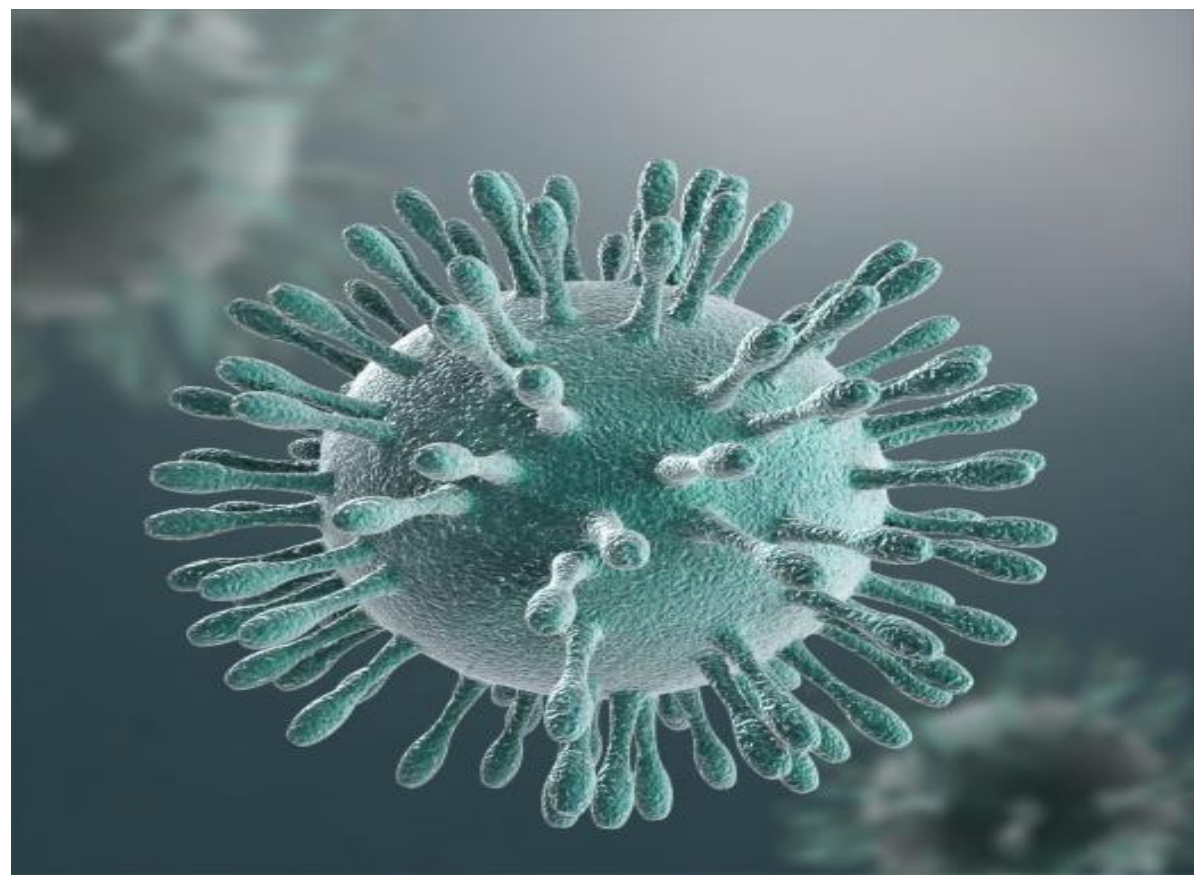

Figure 1: Corona Virus Structure

\section{Signs and Symptoms}

Infection is considered to be fatal among male individuals of age more than 60 years. Older patients with comorbidities seem to be at high risk of developing severe disease as a result of infection with severe acute respiratory syndrome corona virus 2 (SARS-CoV-2) (Chen et al., 2020).

The common clinical symptoms illustrated by the patients suffering from this disease are fever, cough, and shortness of breath, myalgia or fatigue with abnormal chest CT. In more severe cases infection can cause pneumonia, severe acute respiratory syndrome, kidney failure and even death. Similarities of clinical features between COVID-19 and previous beta corona virus infections have been noted as most patients presented with fever, dry cough, dyspnoea, and bilateral ground-glass opacities on chest CT scans. However, few patients with COVID-19 infection had prominent upper respiratory tract symptoms like rhinorrhoea, sneezing, or sore throat, indicating that the target cells might be located in the lower airway (Meng et al., 2020).

\section{Mode of Transmission}

All the human corona viruses are believed to originate from animal reservoirs. Significant research in the last half of the $20^{\text {th }}$ century has seen that these corona viruses cause a large variety of diseases in animals and their ability to cause severe disease in livestock and companion animals such as pigs, cows, chickens, dogs and cats (Fehr et al., 2015). At present, there is no evidence that companion animals can be infected with the novel corona virus. It has been suggested that bats play a role in transmitting the infection to humans; because the virus shows $100 \%$ nucleotide identical to that virus seen in humans (Mirza et al., 2016). Furthermore it is initially reported that the transmission of virus is through seafood market, which is where it is believed to have been emerged (Chen et al., 2020).

Person to person transmission has been suggested as the exposure to infected respiratory droplets produced when the infected person coughs or sneezes (figure 2). These droplets are too heavy to travel far i.e. 
approximately one meter in the air and quickly settle on surfaces. Therefore indirect contact from the contaminated surfaces is also a mode of transmission. Studies have shown that respiratory viruses can be transmitted from person to person through direct or indirect contact, through coarse or small droplets, and can also be transmitted through saliva (Besler et al., 2013). Most corona viruses spread the same way as other cold-causing viruses through infected people coughing and sneezing or by touching an infected person's hands or face. In addition to this there might be risk of fecal-oral transmission, as researchers have identified SARS-CoV-2 in the stool of patients from China and the United States (Meng et al., 2020).

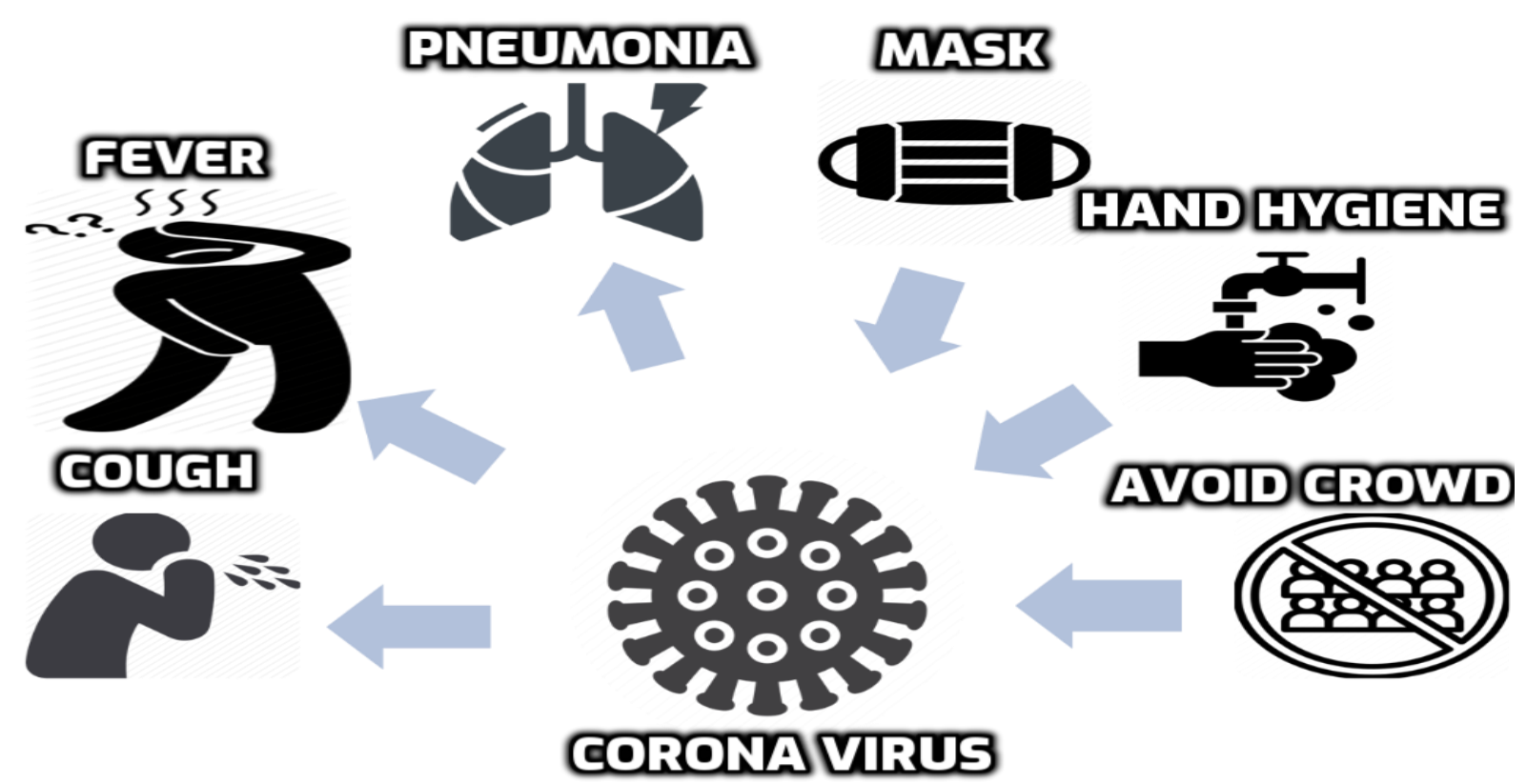

\section{Figure 2: Corona virus symptoms and protective measures}

\section{Recommended Preventive Measures}

In the light of WHO declaring COVID-19 virus to be pandemic, effective and simple preventive measures as recommended by WHO can reduce the risk of infection to one self and others. Clean your hands regularly with an alcohol based rub, soap and water (figure 3,4), cover your mouth and nose with your elbow when you cough or sneeze, stay home when you are sick, avoid unnecessary travel and large social gatherings, and comply with the advice of health authorities (WHO, 2020).

Handwashing with soap and water
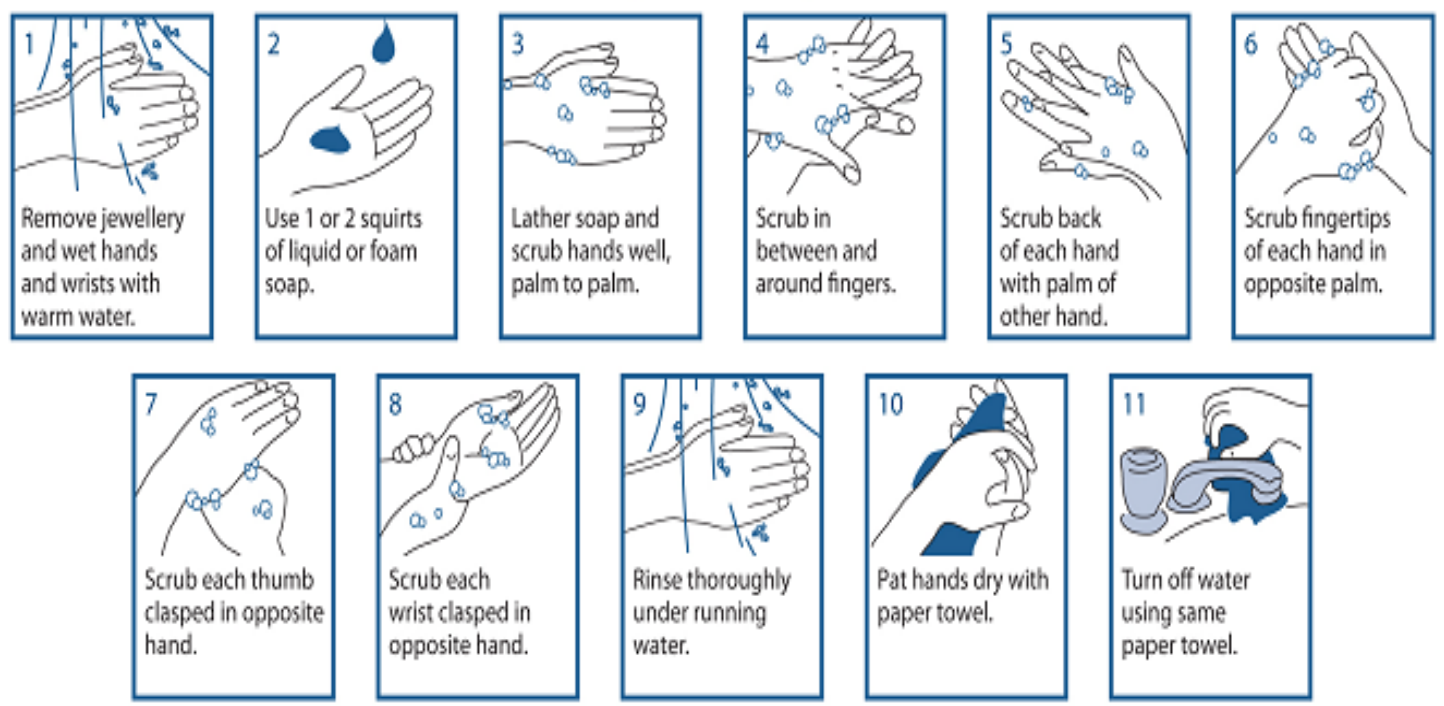

Figure 3: Hand washing with soap and water 
Cleaning with alcohol-based hand rub
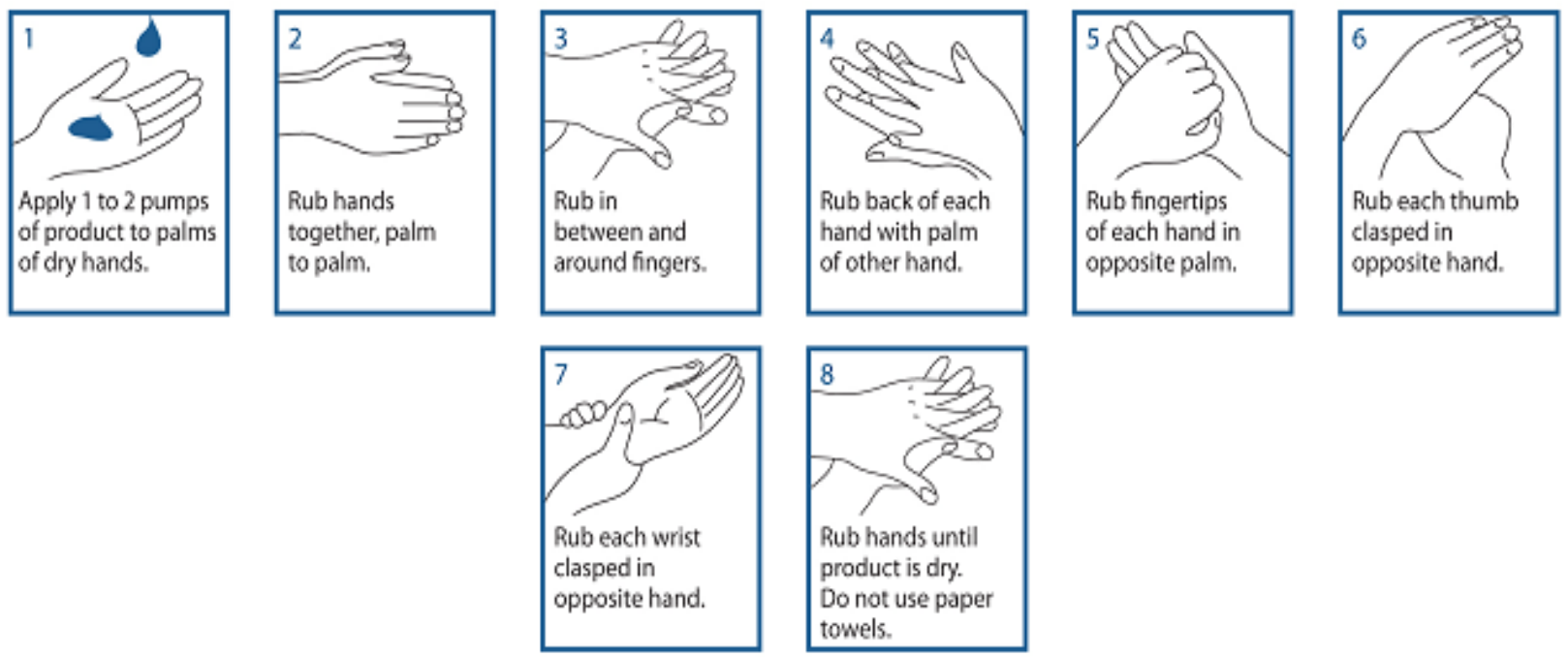

\section{Figure 4: Hand cleaning using a hand rub}

\section{Modes of Transmission To Dental Professionals}

Risk of nosocomial infections is low in Dental settings, although they invariably carry a high risk of novel corona virus infection, which involves frequent communication with the patients, and exposure to saliva, blood, and other body fluids. As this airborne spread is well reported in many studies, droplet and aerosol transmission are most important risk factors for dental professionals in dental clinics. Dental equipment such as dental hand pieces, air-water syringes, ultrasonic scalers and air polishing units produce aerosols during the treatment procedures may get contaminated through patient droplets during the procedures. Direct contact of the dental professionals with human fluids along with the contaminated dental instruments and surrounding surfaces can be another possible route of the spread of virus (Harrel et al., 2004).

\section{Recommended Actions for Dentists}

Foremost duty of a dental professional lies in identifying the patients who show the signs of the infection. Any person suspected or identified with the infection must be immediately referred to higher health centers to prevent the spread of infection.

As the greatest threat of coronavirus comes from aerosols this major route of transmission should be considered. The recommended levels of defense in the reduction of aerosols by Harrel and Molinari for; transmissible based infection control protocols suggested must be followed (Harrel et al., 2004).

Hand hygiene remains at the tip of the pyramid in preventing the spread of the disease. Use of antimicrobial soap with plain running water and alcohol based rubs before and after treating patients can help in curtailing the infection. The use of personal protective barriers such as masks, gloves, eye protection, and face protection will limit the danger inherent in splatter droplets arising from the operative site. Furthermore, the protection provided by surgical masks worn by dental professionals may be low for small particles and are ill-fitting (Chechi et al., 2005). A N95 surgical mask is recommended as it reduces the exposure to airborne particles, from small particle aerosols to large droplets and is tight fitting. However a true aerosol may remain in the air of the operative site for up to 30 minutes after a procedure (Hind 1999 and Al-sehaibany 2017). Therefore if the operator removes a protective barrier such as a face mask to talk to a patient when a procedure is completed, the potential for contact with airborne contaminated material remains.

One method of reducing the virus or bacterial counts produced during dental procedures are through pretreatment mouth rinses. National health commission of the people's Republic of China, advocated that chlorhexidine mouth rinse which is most commonly used during regular dental procedure may not be effective in killing corona virus as chlorhexidine will not affect blood coming directly from the operative site and is unlikely to affect viruses and bacteria harbored in the nasopharynx. Nonetheless corona virus is found to be vulnerable to oxidation, and a pretreatment mouth rinse containing oxidative agents is recommended (WHO, 2020). 
The use of rubber dams can virtually eliminate all contamination arising from saliva or blood. However the use of rubber dam is not feasible for dental procedures, especially for periodontal procedures which are of particular concern as these procedures owe to the greatest amount of aerosol contamination (Harrel et al., 1998).

It has shown high volume evacuators are more effective in minimizing the danger of contaminated aerosols by more than 90\% (Meng et al., 2020). High speed dental hand pieces without anti-retraction valves generally tend to aspirate and splatter the debris and fluids during the dental procedures (WHO, 2020). A study showed that the anti-retraction high speed dental hand piece can significantly reduce the backflow of the oral bacteria and viruses in to the tubes of the hand piece as compared with the hand piece without antiretraction valves (Hu et al., 2007).

Last but not least thorough infection control measures are essential to reduce the spread of this infection despite the usual measures. Regular disinfection of the dental clinics on a daily basis by fumigation and proper disposal of the biomedical waste plays an important role.

\section{Conclusion}

A steady increase in these serious transmissible diseases over the last few decades has created a global concern. It is likely that these viruses will continue to emerge and evolve to cause both human and veterinary outbreaks owing to their ability to recombine, mutate, and infect multiple species and cell types. At last it is we who can have control over the infection, effective preventive measures can always put an end to the explicit outbreak of any infection, that is why it is said- 'prevention is better than cure'

\section{References}

[1.] Abbas $\mathrm{T}$ (2020) Coronavirus in Dentistry. EC Dental Science 19(3):1-2. https://www.ecronicon.com/ecde/pdf/ECDE-19-01370.pdf

[2.] Al-Sehaibany FS (2017) Middle East respiratory syndrome in children: Dental considerations. Saudi medical journal 38(4):339. https://doi.org/10.15537/smj.2017.4.15777

[3.] Belser JA, Rota PA, Tumpey TM (2013) Ocular tropism of respiratory viruses. Microbiology and Molecular Biology Reviews 77(1):144-56. https://dx.doi.org/10.1128\%2FMMBR.00058-12

[4.] Checchi L, Montevecchi M, Moreschi A, Graziosi F, Taddei P, Violante FS (2005) Efficacy of three face masks in preventing inhalation of airborne contaminants in dental practice. The Journal of the American Dental Association 136(7):877-82. https://doi.org/10.14219/jada.archive.2005.0288

[5.] Chen N, Zhou M, Dong X, Qu J, Gong F, Han Y, Qiu Y, Wang J, Liu Y, Wei Y, Yu T (2020) Epidemiological and clinical characteristics of 99 cases of 2019 novel coronavirus pneumonia in Wuhan, China: a descriptive study. The Lancet 395(10223):507-13. https://doi.org/10.1016/S01406736(20)30211-7

[6.] Chen TM, Rui J, Wang QP, Zhao ZY, Cui JA, Yin L (2020) A mathematical model for simulating the phase-based transmissibility of a novel coronavirus. Infectious Diseases of Poverty 9(1):1-8. https://idpjournal.biomedcentral.com/articles/10.1186/s40249-020-00640-3

[7.] Fehr AR, Perlman S (2015) Coronaviruses: an overview of their replication and pathogenesis. In Coronaviruses. Humana Press, New York.

[8.] Harrel SK, Barnes JB, Rivera-Hidalgo F (1998) Aerosol and splatter contamination from the operative site during ultrasonic scaling. The Journal of the American Dental Association 129(9):1241-9. https://doi.org/10.14219/jada.archive.1998.0421

[9.] Harrel SK, Molinari J (2004) Aerosols and splatter in dentistry: a brief review of the literature and infection control implications. The Journal of the American Dental Association 135(4):429-37. https://doi.org/10.14219/jada.archive.2004.0207

[10.] Hinds WC (1999) Aerosol technology: properties, behavior, and measurement of airborne particles. John Wiley \& Sons. 
[11.] Huang C, Wang Y, Li X, Ren L, Zhao J, Hu Y, Zhang L, Fan G, Xu J, Gu X, Cheng Z (2020) Clinical features of patients infected with 2019 novel coronavirus in Wuhan, China. The Lancet 395(10223):497-506. https://doi.org/10.1016/S0140-6736(20)30183-5

[12.] Hu T, Li G, Zuo Y, Zhou X (2007) Risk of hepatitis B virus transmission via dental handpieces and evaluation of an antisuction device for prevention of transmission. Infection Control \& Hospital Epidemiology 28(1):80-2. https://doi.org/10.1086/510808

[13.] Meng L, Hua F, Bian Z (2020) Coronavirus Disease 2019 (COVID-19): Emerging and Future Challenges for Dental and Oral Medicine. Journal of Dental Research 0(0):1-7. https://doi.org/10.1177\%2F0022034520914246

[14.] Mirza MB, Bhagat TV, Inderjit MG, Aljeaidi ZA (2016) Middle East respiratory syndrome and precautions to be taken by dental surgeons. Journal of Health Specialties 4(2):105. 10.4103/1658600X.179821

[15.] Peng X, Xu X, Li Y, Cheng L, Zhou X, Ren B (2020) Transmission routes of 2019-nCoV and controls in dental practice. International Journal of Oral Science 12(1):1-6. https://www.nature.com/articles/s41368-020-0075-9

[16.] World Health Organization (2020) WHO Statement regarding cluster of pneumonia cases in Wuhan, China. World Health Organization. https://www.who.int/china/news/detail/09-01-2020who-statement-regarding-cluster-of-pneumonia-cases-in-wuhan-china

[17.] World Health Organization (2020) World Health Organization- situation dashboard. https://www.who.int/emergencies/diseases/novel-coronavirus-2019

[18.] World Health Organization (2020) World Health Organization Questions and answers on coronaviruses. http://www.emro.who.int/health-topics/corona-virus/questions-and-answers.html 